\title{
What Are the Experiences and Training Needs of Home-Based Carers in Dealing With Diabetes in a Rural Village in South Africa? An Explorative Study
}

\author{
Mamare A. Bopape ${ }^{1}$, Tebogo. M. Mothiba ${ }^{1} \&$ Hilde Bastiaens ${ }^{2}$ \\ ${ }^{1}$ School of Health Care Sciences, Department of Nursing Science, University of Limpopo, South Africa \\ ${ }^{2}$ Department of Primary and Interdisciplinary care, Faculty of Medicine and Health Sciences University of \\ Antwerp, Belgium \\ Correspondence: Mamare A. Bopape, University of Limpopo, Department of Nursing Science Private Bag X1106 \\ Sovenga 0727, South Africa. Tel: 27-15-268-2387, Fax: 27-15-267-3080. E-mail: mamare.bopape@ul.ac.za
}

\author{
Received: November 29, 2018 Accepted: January 8, 2019 Online Published: February 21, 2019 \\ doi:10.5539/gjhs.v11n3p52 \\ URL: https://doi.org/10.5539/gjhs.v11n3p52
}

\begin{abstract}
Type 2 Diabetes Mellitus is a difficult chronic condition associated with morbidity, mortality and loss of quality of life. In Sub-Saharan African countries, HBC (Home-Based Carers) play an important role in the care of people diagnosed with chronic illnesses like diabetes. However, home-based carers seem to lack knowledge to care of people with diabetes because they have not been not formally trained. The aim of this study is to explore and describe the practices, knowledge and learning needs of Home-Based Carers (HBCs) of people with diabetes. A qualitative explorative approach was taken, holding interviews with $15 \mathrm{HBCs}$ at the 4 clinics in the Ga-Dikgale village. The purposive sampling method was used to select participants for this study. Four themes are described: activities performed by HBCs during the care of diabetes patients, existing structures and sources of information for HBCs on the management of diabetic patients, challenges experienced by HBCs during the provision of care to diabetes patients and the learning needs of HBCs, based on how they want their training to be organised. HBCs execute various activities during the care of PWD (patients with diabetes) including providing nutritional advice, medication support, helping with household chores, accompanying patients to healthcare services and dressing their wounds. However, they lack knowledge of issues related to the care of PWD, which makes their role very difficult and challenging.
\end{abstract}

Keywords: diabetes, experiences, training needs, home-based carers

\section{Introduction}

Diabetes Mellitus (DM) has been identified by the World Health Organisation (WHO) as one of the four major types of Non-Communicable Diseases (NCDs) that can lead to complications and increase the risk of premature death (WHO, 2016). Type 2 Diabetes Mellitus (T2DM) is a serious chronic disease associated with morbidity, mortality and loss of quality of life and it constitutes a significant health problem (Muchiri, Gericke, \& Rheeder, 2009; Hughes, Puoane, \& Bradley, 2014). Overall, NCDs, including T2DM are a significant and growing global public problem, affecting all countries and people, irrespective of income. T2DM places a significant economic burden both on healthcare systems and on individuals suffering from the condition (Muchiri et al., 2009). The prevalence of DM in 2014 was 8, $5 \%$ in the adult population globally, compared with $4.7 \%$ in 1980 (WHO, 2016). The prevalence has increased faster in low-and middle-income countries.

South Africa (SA) is ranked as the country with the 2nd highest number of people with DM in the African countries (Phillips \& Steyl, 2014). It was estimated that 3.85 million people in the age group between 21 and 79 years have diabetes. This is 7\% of the same age group in SA (SSA, 2015; IDF, 2015). The burden of NCDs, including DM, in SA, has led to increased workloads, overcrowding oft health facilities and poor quality of care. This has further exerted a strain on human resources in the healthcare system, especially for those working in Primary Health Care (PHC) (Tsolekile, Puoane, Schneiden, Levitt, \& Steyn, 2014).

DM is identified as a chronic disease with different levels of complications that require broad knowledge and good practices to prevent, control and manage them effectively. Early diagnosis and proper management of diabetes' complications can prevent their progression (Hughes et al., 2014). Many patients suffer from the complications of 
DM because of a lack of knowledge about this disease (Gautam, Bhatta, \& Aryal, 2015). Knowledge about prevention and care of DM is very important for individuals and communities, so that they can take action (Muhammad-Lutfi, Zaraihah, \& Anuar-Ramdhan, 2015). Knowledge can reduce the occurrence T2DM and prevent complications in those already suffering from the disease (Kiberenge, Ndegwa, Njenga, \& Mucheni, 2010).

In SA, Home-based carers (HBCs) have been at the forefront of the management of HIV and AIDS from the beginning, caring for and supporting family members and neighbours (NACOSA, 2013). Currently, HBCs, supervised by the nurses at the PHC facilities, offer a package of care to community members, including caring for people diagnosed with chronic illnesses like diabetes mellitus (Aantjies, Quinlan, \& Bunders, 2014). HBCs are non-clinical healthcare providers who work in diabetes' teams. They could assist in improving the quality of diabetic education if they were to receive specialised diabetes training and were supervised by professional nurses (Aponte, 2015). Therefore, HBCs need extensive knowledge to help control and prevent diabetes-related complications (Gautam et al., 2015). A qualitative study conducted on patients and family caregivers on their experiences and practices of care of HIV and diabetes' patients in rural Tanzania revealed that the roles of HBCs when caring for diabetic patients include the following: knowledge and information dissemination to patients and care givers of diabetic patients, disease and treatment monitoring, self-management support in life style changes and the referral of patients to facilities (Mwangome, Geubbels, Klatser, \& Dieleman 2016).

Good knowledge and practices around T2DM among care givers, including HBCs is directly related to the quality of care they provide (Kiberenge et al., 2010). A study conducted in Cape Town demonstrates that HBCs in the study did not have the necessary knowledge to care for diabetes patients. This was indicated by most of them citing the eating of too much sugar as the cause of diabetes and eating less sugar as the primary lifestyle modification suggested to diabetic patients (Hughes et al., 2014). Diabetes-specific education for HBCs is likely to improve diabetes' knowledge, practices and outcomes (Fenwick, Xie, Rees, Finger, \& Lamoureux, 2013). However, based on previous research in the rural SA Ga-Dikgale villages, the HBCs who care for people with diabetes (PWD) seem not to have the relevant knowledge of how to provide care for the patients because they had not been formally trained (Maimela, Van Geertruyden, Alberts, Modjadji, Meulemans et al., 2015). They also found that patients lack respect for HBCs and their work because of their lack of training.

Based on the problems stated above, the aim of the current study is to determine the practices, knowledge and the training needs of HBCs who care for PWD in the Ga- Dikgale village in detail, in order to develop a training programme for HBCs who care for PWD. This in turn will assist the HBCs to improve their service delivery to DM.

\section{Methodology}

The study described in this article is part of a larger project on the development and implementation of a training programme for HBCs who care for PWD in the Ga-Dikgale village in the Limpopo province, South Africa. A mixed method approach was used (de Vos, Strydom, Fouche, \& Delport, 2016; Creswell, 2013; Doyle, Brandy, \& Byrne, 2016). The quantitative part of the study focuses on knowledge, using a questionnaire and the qualitative part of the study focuses on experiences and learning needs. This paper reports on the qualitative part of the study.

Since the researchers wanted to explore the experiences of HBCs caring for PWD, and also to discover their learning needs, a qualitative, explorative, descriptive, contextual approach was used and individual interviews were held to collect data on their experiences and learning needs.

\subsection{Study Site}

The study was conducted at the Ga-Dikgale village under the four clinics where the HBCs work: Dikgale clinic, Seobi Dikgale Clinic, Sebayeng Clinic and, Makotopong clinic. In total, there are 59 HBCs linked to the clinics.

\subsection{Sampling}

Twenty-two HBCs with PWD in their care, from the four clinics, were purposively selected and interviewed after they voluntarily agreed to participate in the study.

\subsection{Data Collection}

The semi-structured, one-to-one interview method with a guide was used to collect data (de Vos, Strydom, Fouche \& Delport, 2016; King \& Horrocks, 2012). A central question which all the participants were asked in the same way was: "How is it for you caring for diabetes mellitus patients in this context?" This was followed by probing, clarity-seeking questions for the researcher to understand the problem (Babbie \& Mouton, 2014). Voice recorders were used to record the interviews and field notes were taken to capture the non-verbal cues. Informed 
verbal and written consent were obtained from every participant before their participating in the study. Interviews were conducted in Sepedi.

\subsection{Data Analysis}

The voice-recordings of the interviews were transcribed verbatim by the researcher and translated into English, in preparation for analysis. In the first stage, familiarisation with the data was accomplished by the researcher's listening to the 22 voice-recorded interviews for accurate translation and transcription. The thematic analysis method was used to analyse the transcripts.

The following stages guided the researcher to produce an insightful analysis to answer the research questions: descriptive coding, interpretive coding and overarching themes (King \& Horrocks, 2012). The researcher gained a sense of the whole by reading and re-reading all the transcriptions carefully to get insight into the data segments and their meaning. The sentences, phrases, paragraphs or lines that were meaningfully related to practices, knowledge and the training needs of HBCs, were transferred to an excel spreadsheet, and descriptive codes were applied.

After the analysis of 3 interviews, descriptive codes were grouped together to create smaller sub-themes and main themes. This codebook was discussed with the supervisors (HB, TM), adapted and consequently used and updated with each new interview analysed, until no new information was found after the analysis of 15 interviews. The remaining data from 7 participants were listened to but not transcribed or included in the analysis. During this process, the researcher reduced the total list by grouping topics that related to one another to create meaning of the themes and sub-themes. Finally, the researcher (MB) again went through the whole data set and a final codebook was created (constant comparison).

\subsection{Quality Assurance}

Transferability was ensured by means of thick description of the research methodology. The purposive sampling method was used to select HBC who care for PWD from the Ga-Dikgale village until data saturation was reached (Brink, van der Walt, \& van Rensburg, 2012). Referential adequacy in this study was accomplished through the usage of a voice recorder and field notes as data collection instruments that were kept together in the same place for future reference (Babbie \& Mouton, 2014). The supervisors of the study have examined the data, and their interpretations and recommendations, to confirm that they are supported by data to ensure credibility.

\subsection{Ethical Standards}

The following ethical standards, informed consent, the right to privacy, the principle of beneficence and permission to conduct the study, were adhered to in this study.

Ethical clearance was obtained from the Turfloop Research Ethics Committee (TREC/76/2016:PG). Permission to collect data in the health facility was obtained from the Department of Health, Limpopo Province and a request to conduct the study was made in writing to the Nursing Managers of the Ga-Dikgale clinics. The participants were informed verbally, and in writing, about the title, purpose and the objectives of the study and the data collection procedures before they agreed to participate in the study. The researcher ensured that participants voluntarily signed the consent forms and that verbal consent was obtained before they were included in the interview sessions. The participants were informed about their right to withdraw from the study at any time and that they would not be forced to continue. The researcher ensured confidentiality by keeping the participant information in a safe place and not using it for non-research purposes, and not sharing it with people not involved in research. Anonymity was maintained by not attaching names to information given to the researcher or in the field notes. The participants were also informed that none of their information with their names would be divulged to any other person. Further, the researcher avoided exposing the participants to any form of harm (de Vos et al., 2016).

\section{Findings}

Fourteen participants were females and only one male. The ages of the participants range from 28 to 49 . Their years of experience range between 3 and 15. The number of PWDs the HBCs care for ranges between 1 and 5 and their level of education is between grade 11 and post-secondary education. (Table 1) 
Table 1. Characteristics of the participants

\begin{tabular}{llllll}
\hline Participant no. & Gender & Age & Experience in years & Level of education & Number of patients \\
\hline 01 & Female & 42 & 9 & Grade 11 & 4 \\
02 & Female & 41 & 15 & Tertiary & 2 \\
03 & Female & 28 & 4 & Grade 12 & 2 \\
04 & Female & 30 & 9 & Grade 12 & 4 \\
05 & Female & 33 & 9 & Grade 12 & 5 \\
06 & Female & 43 & 11 & Grade 12 & 1 \\
07 & Female & 46 & 11 & Grade 12 & 2 \\
08 & Female & 49 & 14 & Tertiary & 3 \\
09 & Female & 36 & 10 & Grade 12 & 1 \\
10 & Female & 35 & 6 & Tertiary & 1 \\
11 & Male & 28 & 8 & Grade 12 & 1 \\
12 & Female & 44 & 14 & Grade 11 & 1 \\
13 & Female & 35 & 9 & Grade 12 & 5 \\
14 & Female & 45 & 3 & Grade 12 & 3 \\
15 & Female & 39 & 13 & Grade 12 & 2 \\
\hline
\end{tabular}

Four broad themes were identified from the thematic data analysis of the interviews. The final code book is described in Table 2. A narrative account of the themes and sub-themes, supported by quotations from participants, follows the table.

Table 2. Themes and sub-themes reflecting experiences and training needs of HBCs who care for PWD in the Ga-Dikgale Village in the Limpopo Province, South Africa

\begin{tabular}{lrl}
\hline Main themes & Sub-themes \\
\hline 1. $\begin{array}{l}\text { Activities taken up by HBCs } \\
\text { during care of diabetes }\end{array}$ & 1.1 & Provision of nutritional needs of PWD is practised \\
patients & 1.2 & Assisting patients to adhere to prescribed treatment (medication support) \\
& 1.3 & Provision of patient-centred care is based on their expectations \\
& 1.4 & Assisting patients with wound dressing \\
\hline 2. $\begin{array}{l}\text { Existing structures and } \\
\text { sources of information for }\end{array}$ & 2.1 & Lack of and existence of on-the-job training for HBC on management of \\
HBCs on management of & 2.2 & PWD \\
diabetic patients & 2.3 & Existence of support for HBC by clinic healthcare professionals \\
\hline 3. $\begin{array}{l}\text { Challenges experienced by } \\
\text { HBCs during provision of } \\
\text { care to diabetes patients }\end{array}$ & 3.1 & Challenges related to knowledge gaps \\
& 3.2 & Challenges related to the beliefs and attitudes of patients \\
& 3.3 & Challenges related to context of PWD (poverty, living alone) \\
\hline 4. Learning needs of HBCs & 3.4 & Difficulties in engaging nurses \\
based on how they want & a) & Suggested training topics to include types of diabetes, signs and symptoms, \\
training to be organised & normal ranges of blood glucose, diabetic diet and complications \\
& b) & Training content to include all procedures and tests done during \\
& c) & Tranagement of PWD \\
& d) & Training topics to include wound care \\
\hline
\end{tabular}




\section{Theme 1: Activities taken by HBCs during provision of care}

HBCs described a number of activities they perform during care of PWDs. These have been clustered into four subthemes.

First, HBCs provide dietary advice to people with diabetes by giving them information. For example, that they are not supposed to eat junk food and fatty food, and also that they must eat correctly to their control sugar intake.

\section{Quotations}

[HBC]....."He can eat 5 times but must not take all the food at the same time. It is not how is done with diabetes. To control sugar is to eat the correct way" [HBC] .... "The other one is that they are not supposed to eat fatty food especially fried food. They must not eat junk food they must learn to follow the correct diet".

Second, the study results indicate that HBCs support diabetic patients to take their medication in a right way and remind them to go to the clinic and collect their medication in time.

Quotations

$[\mathrm{HBC}] . . .$. "We are talking to them about the importance of taking their treatment at the same time, the risks of not taking the treatment at the same time show that diabetes cannot be controlled because you are not taking the treatment at the same time."

Next, HBCs also mentioned that they try to provide personalised care based on the expectations of the patient. This comprises performing household chores and accompanying patients to referred healthcare professionals for further management.

\section{Quotations}

[HBC]....."Sometimes you find that you have to cook for them and fetch water for them. I do most of the things for them". [HBC]....."Most of the time we have a problem because our patients are old people staying alone. Sometimes because our patients are old people staying alone when you go there you find that you are supposed start by cooking for her and do everything for them."

Finally, HBCs are caring for wounds by dressing them and referring patients to hospital if their wounds get worse.

\section{Quotations}

[HBC]....."The patient I am caring for has wound on the leg and when I care for him, I dress the wound".

Theme 2: Existing structures, sources of information and support for HBCs on the management of diabetic patients

HBCs outlined various structures, sources of information and support available during the management of diabetic patients. They are clustered into three sub-themes:

Firstly, some HBCs indicated the existing on the job training which focuses on TB and HIV and superficially addresses diabetes mellitus; some have not attended any training but have learned what they know from the clinic and families.

\section{Quotations}

[HBC]..... "I have attended a course introduced by Department of Health called re-engineering but it was more about HIVIAIDS and TB. But at the end they talked about diabetes where they were explaining that statistics shows there is a link HIVIAIDS and diabetes this days unlike before where we knew that it is only linked to TB. So now diabetes is linked to HIV/AIDS and they just made us aware of the symptoms of diabetes." [HBC]..... "No, I have never attended training it is just that somewhere somehow I have learned it because in my family we have diabetic patients."

Secondly, HBCs use different sources for information, including patients, family, dieticians, clinics, the Department of Health and magazines, when caring for diabetes mellitus people.

\section{Quotations}

[HBC]...... "The patient showed me how to inject herself because she said one day you will find me unresponsive and you must inject me. That is how I have learned to inject the patient - taught by the patient. The other patients were having normal diabetes on normal treatment." [HBC]...... "I was taught how to test sugar. At home we have a diabetic patient. My father is diabetic and we were pricking him every day in the morning testing his sugar to see if it has dropped or is high" [HBC]...... "I have never attended training it is just that somewhere somehow I have learned it because in my family we have diabetic patient. I have learned there and there." [HBC].... "The things 
that I know about diabetes I have learned from the clinic. I just ask at the clinic how to care for a diabetic patient if is in a certain condition."

Finally, HBCs receive support from the clinic healthcare professionals like nurses and dieticians.

$[\mathrm{HBC}] . . .$. "Support we get it from our nurses at the clinic. They advise us on how to work when a patient has diabetic. Sometimes they tell me that if you find the patient not well you must just do call back and they will come and check the patient to see if the sugar is high or low". [HBC]...... "We get support from the dieticians because sometimes they go with us to see the patients. They teach the patients about the food that they are supposed to eat. They are the people that give us support". [HBC]..... "The other people who give us support are the nurses working at mobile clinics because sometimes when we encounter challenges, they go with us and show us to do some of the things like dressing of the wounds".

\section{Theme 3: Challenges experienced by HBCs during the provision of care to diabetic patients}

HBCs described challenges they experience when providing care to diabetic patients. They are grouped into four sub-themes, namely lack of knowledge, patients' behaviour and attitudes, context of the patient and nurse-related challenges.

First, HBCs have different levels of knowledge related to diabetes mellitus. Based on their accounts, the researcher observed that there is a lack of knowledge, although some HBCs do have some knowledge on some topics.

\section{Quotations}

$[\mathrm{HBC}] . . . .$. "I know a little about how they are supposed to eat and that if sugar is low they can eat a sweet." $[\mathrm{HBC}] . . .$. So these are some of the things I know like you will find that some use the tablets when drinking tea not sugar. Even with their injections they must be stored in the fridge not it is warm and not cold". [HBC]...... test the patient sugar if the patient has the machine to check sugar if is normal or not normal. If is normal you will find that it is 5-7. It must not be above seven and if is low it must not be in the middle and it must not drop to one."

This lack of knowledge of HBCs makes it difficult for them to fulfil their role.

\section{Quotations}

[HBC]..... It is hard sometimes because we do not understand their condition as we are not trained on how to care for diabetic patients, I know nothing about diabetes". [HBC]..... "It is difficult because we have diabetic patients but if the patient has complicated you do not know as to whether you must give the patient sugar or what". $[\mathrm{HBC}] . . . . .$. "It is hard sometimes because we do not understand their condition as we are not trained on how to care for diabetic patients".

HBCs experience challenges with the patients' beliefs because they believe that wounds are not due to diabetes but to witchcraft and the ancestors are against their being pricked with needles.

$[\mathrm{HBC}] . . . .$. ."The challenge that I have is with the patients who have wounds, because one of the patients that I care for have a wound that started very small and when I tell her that this must be due to diabetes and she said no, she is bewitched". [HBC]..... "Others have cultural beliefs when it come to the needles that are used to check sugar because they say that their ancestors do not agree for them to be pricked with needles. Even when we are supposed to check their HIV status they will refuse to be pricked".

The results of the study demonstrate that the context of diabetic patients also poses challenges for HBCs. They experience that poverty impedes patients from seeking care as they have no money for transport and they cannot afford the diet they must follow. Participants also mentioned that older patients who live alone struggle with access to care.

\section{Quotations}

[HBC] ....."To care for diabetic patient is very difficult because some cannot afford the diet that they must follow". $[\mathrm{HBC}] . . . .$. "The problem that we experience is that sometimes you find that there is no treatment at the clinic and you find that they give them letters to go and collect treatment at the hospital and the patient does not have money for transport. The patient will just stay at home without treatment". [HBC]....."The patient can tell you that I have this problem and even if you can refer the patient to the clinic no one will take her there because she is staying alone".

HBCs are faced with problems when trying to engage nurses because nurses have transport challenges and cannot come to help HBCs at home; and they also mention attitude problems. 


\section{Quotations}

[HBC]....."Like when we have challenges, we can go to the nurses and ask for help, but their biggest challenge is transport because our areas are far apart and they can only go and help in areas that are next to the clinic. The problem is that when you go to the patient sometimes you find the patient in a state that you cannot manage as a $H B C$, the care that is needed is above your scope and you call the nurses to come but they do not have transport". [HBC]..... "Sometimes it is difficult when you need help from the nurses because some of the nurses will tell you that they are busy and you will wait until you realise that this person does not want to help you".

Theme 4: Learning needs of HBCs related to the care of diabetic patients based on how they want training to be organised

HBCs indicated a number of aspects of diabetes mellitus they would like to be trained on. The identified training topics have been clustered together into four sub-themes;

Firstly, HBCs suggested that training topics include: the types of diabetes, signs and symptoms, normal ranges of blood glucose, diabetic diet and complications.

One of the HBCs indicated that she wanted to learn about different types of diabetes because she knows that some take pills and others use injections. She also wanted to understand type 1 and type 2 better.

\section{Quotations}

$[\mathrm{HBC}] . . .$. "I want to know the differences between the types of diabetes because I know that the others take pills and the others use injections" [HBC]..... "I think if I can be educated about that including diabetes type 1 and type 2, so that I can understand them better"

HBCs indicated that they need to learn about signs and symptoms of diabetes mellitus that they may observe and that they can report.

\section{Quotations}

[HBC]...... "I also want to learn about signs and symptoms that I can observe so that I can be able to tell a person that I think you have diabetes therefore go to the clinic for testing".

HBCs indicated the need to learn about normal ranges of blood glucose to enable them to interpret the results from the clinic and to identify whether a patient's blood glucose is controlled.

\section{Quotations}

$[\mathrm{HBC}] . . .$. "Ok I also want to know the levels of sugar when they say is low is between these numbers and when they say it is high it is between these numbers. I think these are the things that we must know as home-based carers."

The study results show that HBCs need to learn about a diabetic diet, including food that diabetic patients should eat, how often they should eat and how to prepare the food.

\section{Quotations}

[HBC].... "I want to learn about the food that they are supposed to eat. Food that is good for diabetic patients". [HBC]....."I also want to learn about which food they must eat, how often and how to prepare the food". [HBC].... "I must also learn about diabetic diet, the type of food that the patient must eat".

HBCs indicated the need to learn about the complications of diabetes mellitus because they do not know how diabetes affects male manhood and also how it may cause kidney damage.

Quotations

[HBC]....."I also want to know concerning males and diabetes because I heard that it affects their manhood, because I heard that there is a problem with male and that cannot be the same with females because it cannot be easily discovered with females. I want to know if it is correct and if is correct how can they be helped".

Secondly, HBCs want to learn about all procedures and tests done during the management of diabetes patients including blood glucose tests using machines and urine tests.

\section{Quotations}

[HBC].....”Yes, I want to know how to check the sugar level, test the patient sugar if the patient has the machine to check sugar if is normal or not normal". [HBC]..... "My patient has a machine that was given to her so that she can check her sugar level. Sometimes she ask me to help check her sugar level and I tell her I don't know how to use the machine. Maybe if they can just teach us how to check sugar level using machine it will be better". 
Thirdly, HBCs wanted to be trained about different treatments given for specific types so that they know about diabetic treatment and understand why some get injections.

\section{Quotations}

$[\mathrm{HBC}] . . . .$. "I need to learn about diabetic treatment so that when I check treatment I must know that this is diabetic treatment so that I can be able to give health education about the treatment that I know". $[\mathrm{HBC}] . . . .$. "Even the injections that the others are getting I need to understand why they are getting the injections how do the injections work. I want to know about the tablets and injections and how they work".

Finally, HBCs highlighted the need to learn about wound care, including the dressing of the wounds.

\section{Quotations}

$[\mathrm{HBC}] . . . .$. Sometimes they tell you that you need to take care of this patient and when you arrive you find that the patient has a wound and you are expected to dress the wound. I think we need to be trained on how to dress the wound because you are just doing what you think is right, but you are not sure".

\section{Discussion}
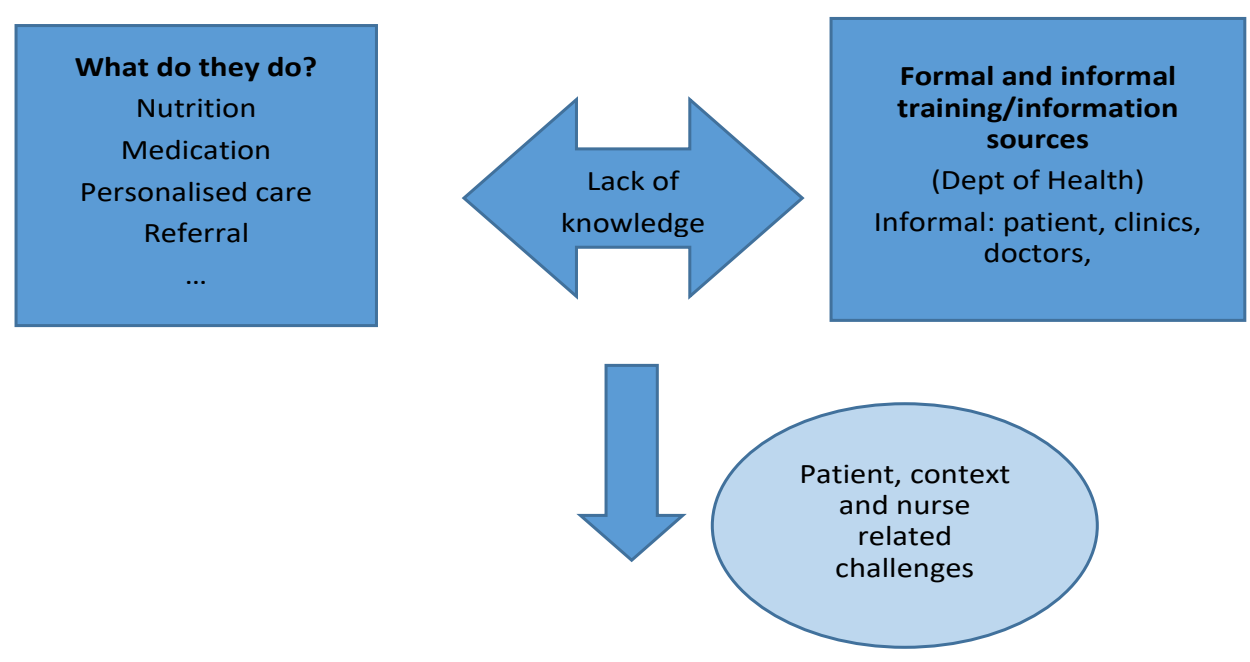

Training needs

Types of Diabetes, Signs and symptoms,

Diabetic diet, Normal ranges of blood

glucose, diabetic complications, diabetic treatment

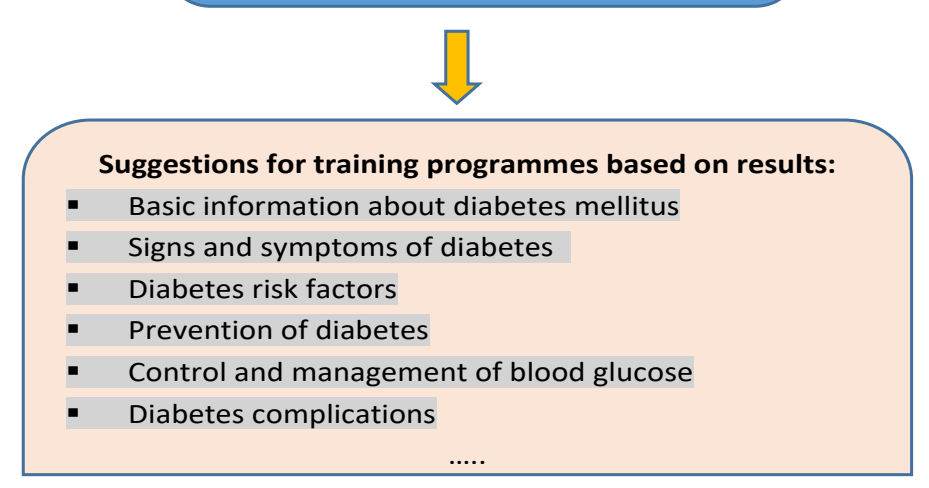

Figure 1. Thematic map

To prepare the development of a training programme on T2DM for HBCs, this study explores and describe the experiences and the training needs of HBCs who care for PLWD in the Ga- Dikgale village, a rural area in South Africa. Figure 1 indicates the relationship between the experiences and the learning needs of the HBC as discussed below: 
The findings provide a picture of the activities carried out by HBCs when they care for PWDs. Consistent with the finding of other studies, it was found that HBCs provide nutritional information, assist with treatment adherence, provide patient-centred care based on expectations and they dress wounds (Tsolekile et al., 2014; Benjamin, 2012; Bhojani, Mishra, Amruthavalli, Devadasan, Kolsteren, Henauw, \& Criel, 2015; Mattila, Leino, Kemppi, \& Tuominen, 2011; Hangulu \& Akintola, 2017). Contrary to these findings, the study conducted by Tsolekile and others discovered that there was a lack of adherence support given to clients with NCDs, including DM, compared with the extensive support provided by HBCs to patients with HIV infections and TB treatment (Tsolekile et al., 2014). The fact that HBCs take up various activities to assist PWDs is an indication of the significant role they play in their care. This further demonstrates the ability of HBCs to react to the needs of PWDs.

The current study documents that HBCs experience challenges during the care of PWDs. These are related to the beliefs and attitudes of patients, the context of PWDs, elderly patients living alone, difficulties in engaging nurses during the provision of care to people with diabetes, and the training and knowledge of the HBCs themselves. These study findings are similar to the results of other studies (Hughes et al., 2014; Bhojani et al., 2015; Mendenhall, Shivashankar, Tandon, Ali, Narayan, \& Prabhakaran, 2012). The challenges create a problem for HBCs by preventing them from providing quality care to PWDs.

This study shows that HBCs have not attended training on DM. This is supported by another study that found that insufficient training is reflected in the poor knowledge of PWDs (Hangulu \& Akintola, 2017). HBCs received information related to diabetes informally from the patients, families, clinics and doctors, and some formal training from the Department of Health through PHC re-engineering workshops. In support of the findings of our work, the study by Hussain, Rajesh, Giridhar, Gopalakrishnan, Sadasivan, James and John, (2016) indicates that HBCs gained information about diabetes mellitus from general practitioners and physicians. The concerning problem is that the information they receive from the above sources is not comprehensive and causes confusion to the HBCs. Furthermore, some of the information offered might be incorrect leading to HBCs' work being devalued. Therefore, such inadequacies in practice indicate insufficiency in knowledge, pointing to the need for adequate training to ensure good practice.

Although HBCs take on various activities in providing care to PWD, they lack knowledge related to the condition of DM, care of PWDs and the management of diabetic complications. The lack of knowledge of HBCs might be a result of the fact that they have not attended any DM training. The lack of knowledge uncovered in this study is consistent with other studies (Hughes et al., 2014; Tsolekile et al., 2014; Muninarayana, Balachandra, Hiremath, Iyengar, \& Anil, 2010; Irvin, Ashbaugh, \& Mehta, 2015). The fact that HBCs lack knowledge is worrying because of the negative impact it has on the care of and the information provided to PWDs.

HBCs need to be trained about DM to improve their knowledge and skills to enable them to better care for diabetic people. Similar findings have been found by other researchers, indicating the need for training of HBCs on diabetes mellitus (Hughes et al., 2014; Tsolekile et al., 2014; Muninarayana et al., 2010). The HBCs indicated aspects of DM they need to be learn about including types of diabetes, normal ranges of blood glucose, signs and symptoms, complications and diabetic diet. The suggested topics for training are consistent with other studies (Hughes et al., 2014; Hangulu \& Akintola, 2017; Gaziano, Abrahams-Gessel, Denman, Montano, Khanam, Puoane, \& Levitt, 2015; Ramachandran, 2014; Desalu, Salawu, Jimoh, Adekoya, Busari, \& Olokoba, 2011). Well-trained HBCs will be able to perform as formally trained health professionals (Gaziano et al., 2015). In a next step of this study, the researchers develop a training programme, based on the training needs emerging from this step.

\subsection{Limitations and Strengths}

This study was only conducted in the Ga-Dikgale village and therefore the results cannot be transferred to other areas. However, the findings are relevant for the Ga-Dikgale region and might also be relevant to similar rural settings. By describing the context and methodology in detail, other researchers and practitioners can judge the usefulness of these findings for their settings.

\section{Conclusion}

HBCs carry out various activities during the care of diabetic patients, including giving advice on nutritional needs, medication support, household chores, accompanying patients to healthcare services and wound dressing. However, HBCs lack knowledge of issues related to the care of PWDs, which makes their role very difficult and challenging. Therefore, it is important that Home-Based Carers are trained by those with knowledge, in order to empower them, to care for patients and to improve their quality of life. 


\section{Funding}

This study was supported by the Flemish Inter-university Council (VLIR UOS Limpopo project), Grant Number: ZIUS2018AP021.

\section{Competing Interests Statement}

The authors declare no potential conflicts of interest with respect to this article.

\section{References}

Aantjies, C., Quinlan, T., \& Bunders, J. (2014). Integration of community home based care programmes within national primary health care revitalization strategies in Ethiopia, Malawi, South-Africa and Zambia: a comparative assessment. Globalization and Health, 10(85).

Aponte, J. (2015). Diabetes Training for Community Health Workers. Journal of Community Medicine \& Health Education, 5(6), 378. https://doi.org/10.4172/2161-0711.1000378

Babbie, E., \& Mouton, J. (2014). The Practice of Social Research. Cape Town. Oxford University press.

Benjamin, R. M. (2012). Medication Adherence: Helping Patients Take their Medicines as Directed. Public Health Reports, 127(1), 2-3. https://doi.org/10.1177/003335491212700102

Bhojani, U., Mishra, A., Amruthavalli, S., Devadasan, N., Kolsteren, P., De Henauw, S., \& Criel, B. (2013). Constraints faced by urban poor in managing diabetes care: Patients' perspectives from South India. Global Health Action, 6. https://doi.org/10.3402/gha.v6i0.22258

Brink, H., van der Walt, C., \& van Rensburg, G. (2012). Fundamentals of research Methodology for healthcare professionals (3rd ed.). Cape Town. Juta.

Creswell, J. (2013). Qualitative Inquiry and Research Design: Choosing Among Five Approaches (3rd ed.). Washington DC. Sage.

Desalu, O. O., Salawu, F. K., Jimoh, A. K., Adekoya, A. O., Busari, O. A., \& Olokoba, A. B. (2011). Diabetic foot care: self-reported knowledge and practice among patients attending three tertiary hospitals in Nigeria. Ghana Med J, 45(2), 60-5.

de Vos, A., Strydom, H., Fouche, C., \& Delport, C. (2016). Research at Grass roots. For the Social Sciences and Human Services Professions (3rd ed.). Pretoria: JL Van Schaik.

Doyle, L., Brandy, A., \& Byrne, G., (2016). An overview of mixed methods-research -revisited. Journal of Research in Nursing, 21(8), 623-635. https://doi.org/10.1177/1744987116674257

Fenwick, E. K., Xie, j., Rees, G., Finger, R. P., \& Lamoureux, E. L. (2013). Factors associated with knowledge of diabetes in patients with type 2 diabetes using Diabetes Knowledge Test validated with Rasch analysis. PLoS One, 3, 8(12). https://doi.org/10.1371/journal.pone.0080593

Gautam, A., Bhatta, D. N., \& Aryal, U. R. (2015). Diabetes-related health knowledge, attitude and practice among diabetic patients in Nepal. BMC Endocr Disord, 5(15), 25. https://doi.org/10.1186/s12902-015-0021-6

Hangulu, L., \& Akintola, O. (2017). Health care waste management in community-based care: experiences of community health workers in low resource communities in South Africa. BMC Public Health, 17, 448. http://dox .doi.10.1186/s12889-017-4378-5

Hughes, G. D., Puoane, T., \& Bradley, H. A. (2014). Ability to manage diabetes - Community health workers' knowledge, attitudes and beliefs. Journal of Endocrinology, Metabolism and Diabetes of South Africa, 11(1), 10-14. https://doi.org/10.1080/22201009.2006.10872134

Hussain, R., Rajesh, B., Giridhar, A., Gopalakrishnan, M., Sadasivan, S., James, J., \& John, N. (2016). Knowledge and awareness about diabetes mellitus and diabetic retinopathy in a suburban population of a South Indian state and its practice among the patients with diabetes mellitus: A population-based study. Indian Journal of Ophthalmology, 64(4), 272-276. https://doi.org/10.4103/0301-4738.182937

Irvin, T., Ashbaugh, S. J., \& Mehta, K. (2015). Knowledge of diabetes mellitus among community health workers in rural Kenya. http://dox.doi.org/10. 1016/j.aogh. 2015. 02.712

Kiberenge, M. W., Ndegwa. Z. M., Njenga, E. W., \& Mucheni, E. W. (2010). Knowledge, attitude and practices related to diabetes among community members in four provinces in Kenya: a cross-sectional study. Pan Afri Med J. 7(2).

King, N., \& Horrocks, C. (2012). Interviews in Qualitative Research. Thousand Oaks, California. Sage. 
Maimela, E., Van Geertruyden, J., Alberts, M., Madjadji, S. E. P., Meulemans, H., Fraeyman, J., \& Bastiaens, H., (2015). The perceptions and perspectives of patients and health care providers on chronic diseases management in rural South Africa: a qualitative study. Biomed Central Health Services Research, 15(143).

Mattila, K., Leino M., Kemppi, C., \& Tuominen, R. (2011). Perceived disadvantages caused by low back pain. $J$ Rehabil Med., 43, 684-8. https://doi.org/10.2340/16501977-0835

Mendenhall, E., Shivashankar, R., Tandon, N., Ali, M. K., Narayan, K. M. V., \& Prabhakaran, D. (2012). Stress and diabetes in socioeconomic context: A qualitative study of urban Indians. Soc Sci Med., 75, 2522-9.

Muchiri, J. W., Gericke, G., \& Rheeder, P. (2009). Elements of effective nutrition education for adults with diabetes mellitus in resource-poor settings: A review. Health SA Gesondheid, 14(1), 9. https://doi.org/10.4102/hsag.v14i1.413

Muhammad-Lutfi, A. R., Zaraihah, M. R., \& Anuar-Ramdhan, I. M. (2014). Knowledge and Practice of Diabetic Foot Care in an In-Patient Setting a Tertiary Medical Centre. Malays Ortop J., 8(3), 22-6. https://doi.org/10.5704/MOJ.1411.005

Muninarayana, C., Balachandra, G., Hiremath, S. G., Iyengar, K., \& Anil, N. S. (2010). Prevalence and awareness regarding diabetes mellitus in rural Tamaka, Kolar. International Journal of Diabetes in Developing Countries, 30(1), 18-21. http://dox.doi.org/10.4103/0973-3930.60005

Mwangome M. N., Geubbels, N. E., Klatser, P., \& Dieleman M. (2016). "I don’t have options but to persevere.” Experiences and practices of care for HIV and diabetes in rural Tanzania: A qualitative study of patients and family caregivers. International Journal for Equity in Health, 15, 56. https://doi.org/10.1186/s12939-016-0345-5

NACOSA. (2013). Position Paper. Community Care Workers: Recognition of Home based carers.

Phillips, J. S., \& Steyl, T. (2014). Physical activity among urban community dwellers with diabetes mellitus: An exploration of experiences. African Journal for Physical, Health Education, Recreation and Dance (AJPHERD), Supplement 2(1), 218-227.

Ramachandran, A. (2014). Know the signs and symptoms of diabetes. The Indian Journal of Medical Research, 140(5), 579-581.

Statistics South Africa. South Africa. (2015). Mid-year-population estimates. Retrieved from http://.statssa.gov.za/publications/P0302/P03022015.pdf

Tsolekile, L. P., Puoane, T., Schneiden, H., Levitt, N. S., \& Steyn, K. (2014). The roles of community health workers in management of non-communicable diseases in an urban township. Afr J Prim Health Care Fam Med., 6(1), E1-8. https://doi.org/10.4102/phcfm.v6i1.693

\section{Copyrights}

Copyright for this article is retained by the author(s), with first publication rights granted to the journal.

This is an open-access article distributed under the terms and conditions of the Creative Commons Attribution license (http://creativecommons.org/licenses/by/4.0/). 